\title{
US claims of 'no chemical links' to Gulf War illnesses under fire
}

[WASHINGTON]. The controversy surrounding claims of a 'Gulf War syndrome' took a new turn last week, when a US presidential panel reported that the ill-defined collection of maladies could not be tied to chemical weapons or other environmental exposures in the Persian Gulf.

The following day, the lead author of three new scientific papers suggested exactly the opposite at a press conference. And the papers' conclusions were immediately used by members of a Senate committee to attack the advisory panel's conclusions as being too conservative.

On 7 January, President Bill Clinton accepted the findings of the Presidential Advisory Committee on Gulf War Veterans' Illnesses, which he had set up in May 1995 to investigate the mysterious afflictions reported by tens of thousands of Gulf War veterans.

Its 126-page report sharply criticized the Pentagon for laxity in investigating troops' possible chemical and biological exposures. But it found no scientific evidence of a causal link between veterans' illnesses and exposures to various environmental agents including chemical weapons - in the Gulf.

The panel also concluded that stress was likely to be "an important contributing factor" to the range of physical and psychological symptoms reported by veterans. It recommended that federal research on Gulf War illnesses should focus more on the physiological effects of stress.

But the following day, the editor of the Journal of the American Medical Association (JAMA) announced that this week's issue of the journal would carry three papers suggesting that exposure to combinations of chemicals - including chemical nerve agents, government-issued insect-repellent, and a drug taken to prevent nerve-gas poisoning - appear to be responsible for specific neurological syndromes in veterans.

"The findings of our study provide, to our knowledge, the first epidemiologic evidence of associations between environmental risk factors and systematically defined syndromes in Gulf War veterans," the authors of the papers write.

At a news conference, Robert Haley, director of epidemiology at the University of Texas Southwestern Medical Center, Dallas, and lead author of the three JAMA papers, said: "This will give veterans a lot of heart." Referring to joint and muscle pain, depression, chronic fatigue, skin rashes and chronic diarrhoea reported by Gulf veterans, Haley said that his work "probably explains all these unusual symptoms".
The papers' findings were immediately picked up by politicians from both political parties, who used them at a Senate hearing on 9 January to attack the president's committee for being too conservative both in its report and in its reaction to the new studies. There is "a lot of evidence" about a causal connection, said Arlen Specter (Republican, Pennsylvania), the new chairman of the Senate Veterans' Affairs Committee. "We need to pinpoint it."

But Philip Landrigan, director of environmental and occupational medicine at Mount Sinai School of Medicine in New York, and a member of the presidential panel, argued at the hearing that the selection methods and relatively small sample size (23) in one of the JAMA studies made it impossible to generalize its findings to the 697,000 US Gulf War veterans. The papers "don't prove the point," said Landrigan. "They raise the question. They suggest the urgent need for further research."

Landrigan's arguments also appear in an accompanying JAMA editorial in which he writes that the Haley studies "have limitations that substantially weaken the authors' strong conclusions". This did not prevent Jay Rockefeller (Democrat, West Virginia), the senior committee Democrat, from lambasting the presidential panel for an "overriding focus" on stress as a source of post-Gulf War illnesses.

He called this a "wonderful excuse" for the government to ignore chemical agents that could be the source of illness. He suggested that independent studies - as opposed to those sponsored by the US government - were finding chemical causes for the illnesses afflicting veterans.

The chair of the presidential committee, Joyce Lashof, a former dean of the school of public health at the University of California at Berkeley, immediately challenged Rockefeller. "Not all independent research goes in that direction," she said. She added that her committee's conclusions were drawn from a review of both government-sponsored and independent research.

The first JAMA paper uses factor analysis to derive various neurological syndromes, which were found among 25 per cent of the veterans studied. The second documents diffuse neurological abnormalities among 23 veterans with one of three primary syndromes. The third links the syndromes to different chemical exposures.

'Impaired cognition syndrome' (including difficulty remembering, depression and insomnia) occurred more frequently in

\section{IMAGE UNAVAILABLE FOR COPYRIGHT REASONS}

Fighting for breath? Stress, rather than chemical agents, may have caused 'Gulf War syndrome'.

subjects who reported wearing flea and tick collars containing the pesticide chlorpyrifos.

'Confusion-ataxia syndrome' (thinking, reasoning, and balance problems) occurred eight times more often among veterans who believed they had been exposed to chemical weapons. This effect was synergistically amplified in veterans who had serious adverse reactions to the anti-nerve gas medication pyridostigmine bromide (PB).

In addition, 'arthro-myo-neuropathy syndrome' (joint and muscle pain) occurred more frequently with increasing use of government-issued insect-repellent containing the chemical DEET.

The researchers say that the neurological syndromes are "best explained" as variants of a syndrome of nerve damage called organophosphate-induced delayed polyneuropathy "resulting from exposure to combinations of organophosphates and other cholinesterase-inhibiting chemicals, including nerve agents, pesticides, insect repellents and pyridostigmine bromide".

The presidential committee recommended research on the long-term effects of low-level exposure to chemical nerve agents, and the synergistic effects of exposure to $\mathrm{PB}$ with other Gulf War risk factors. It called for an independent investigation of troops' possible exposure to chemical and biological warfare agents, and criticized Pentagon investigations as "superficial".

Government departments have been given 60 days to draw up a plan for implementing the committee's.recommendations. The committee's life has been extended for nine months, allowing it to oversee the implementation of its recommendations, and to oversee a Pentagon investigation of possible biological and chemical exposures of Gulf War troops.

Meredith Wadman 